\title{
Surgical technique: complex glaucoma case requiring Molteno drainage tube extension
}

This article was published in the following Dove Press journal:

Clinical Ophthalmology

| March 201 |

Number of times this article has been viewed

\author{
Mohammed Sohaib Mustafa \\ Augusto Azuara-Blanco \\ Department of Ophthalmology, NHS \\ Grampian, Aberdeen Royal Infirmary, \\ Aberdeen, UK
}

\begin{abstract}
A 42-year-old man has been under long-term follow-up since he was a child for congenital glaucoma and buphthalmos in both eyes. His left eye best corrected visual acuity (BCVA) was counting fingers, due to end-stage glaucoma. He was on maximal medical therapy with an intraocular pressure (IOP) maintained at mid to low twenties. His right eye, the only seeing eye, had a BCVA of 6/9. This eye had undergone multiple glaucoma laser and surgical procedures, including an initial first Molteno drainage device inserted superonasally that failed in April 2003 due to fibrotic membrane over the tube opening. As a result, he subsequently had a second Molteno drainage device inserted inferotemporally. To further maximize his vision he had an uncomplicated cataract extraction and intraocular lens implant in December 2004, after which he developed postoperative cystoid macular edema and corneal endothelial failure. He underwent a penetrating keratoplasty in the right eye thereafter in March 2007. After approximately a year, the second Molteno device developed drainage tube retraction, which was managed surgically to maintain optimum IOP in the right eye. His right eye vision to date is maintained at $6 / 12$.
\end{abstract}

Keywords: buphthalmos, congenital glaucoma, penetrating keratoplasty, Molteno drainage device

\section{Case report}

Congenital glaucoma and resultant buphthalmos are very difficult conditions to manage. If intraocular pressure (IOP) is not controlled in early childhood, this can result in devastating consequences for the patient's vision. This was the case with our patient, such that his left vision was very poor. As a result of coexisting left amblyopia and glaucoma, the eye had poor vision at best corrected visual acuity (BCVA) of hand movements. His left eye IOP was well controlled in the low twenties with maximal medical therapy, namely cosopt bd, brimonidine bd, latanoprost nocte, and pilocarpine $2 \%$ qds. As a child in the $1970 \mathrm{~s}$, the patient had had a trabeculectomy in this eye that failed. The main aim for the eye was to keep it comfortable with IOP control.

The right eye had a small island of central vision remaining. As a result, the right eye underwent interventional management to try to control the IOP when pressures were high/spiking, as it was the only eye with useful vision at BCVA 6/9 (see Figure 1). Target IOP was 10-11 mm Hg.

In addition to medical therapy, the patient had iridencleisis procedures as a child in his right eye. He subsequently went on to have a Molteno drainage device implant superonasally for uncontrolled IOP at $43 \mathrm{~mm} \mathrm{Hg}$ in 1990. Over the course of 1 year, the IOP remained unsettled despite subconjunctival 5-fluorouracil (5-FU) and cyclocryotherapy.
Mustafa

Eye Clinic, Aberdeen Royal Infirmary,

Foresterhill, Aberdeen AB25 2ZN

Scotland, UK

Tel +44 I22 45532 I

Fax +441224553213

Email mmustafa2@nhs.net 


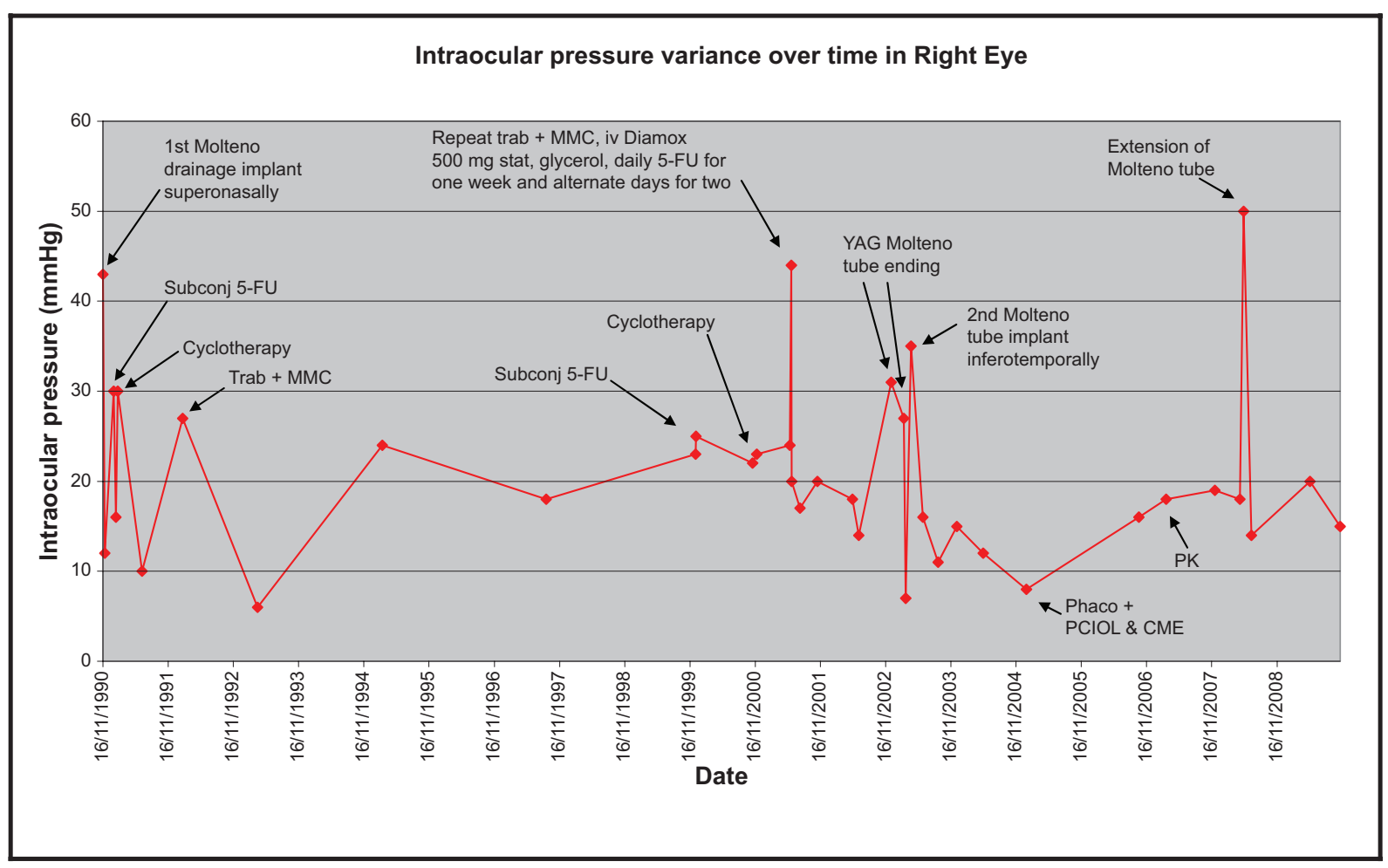

Figure I Graph showing IOP (mm Hg) variance over time in the right eye with points of intervention when there was a spike in IOP.

Abbreviations: 5-FU, 5-fluorouracil; IOP, intraocular pressure; MMC, mitomycin-C; phaco, phacoemulsification; subconj, subconjunctival; trab, trabeculectomy; YAG, yttrium aluminium garnet. CME, cystoid macular edema; PCIOL, posterior chamber intraocular lens; PK, penetreting keratoplasty.

This was noticed by the patient as repeated intermittent haloes throughout the day. This was likely due to pressure spikes. The right eye underwent a trabeculectomy + mitomycin-C (MMC) in 1992 when the IOP was successfully reduced to low twenties with additional medical treatment. In 2001, he had a repeat trabeculectomy $+\mathrm{MMC}$ and subsequent repeated 5-FU injections over 3 weeks to reduce fibrotic drive. This proved to be successful for only 1 year. Thereafter, similar symptoms of haloes returned. A fibrotic membrane over the Molteno tube opening was treated with neodymium-doped yttrium aluminium garnet laser twice unsuccessfully.

The Molteno tube had then retracted and needed repositioning, but unfortunately the pressure reduction was short lived and therefore a second Molteno drainage implant was positioned inferotemporally. This proved to be by far the most lasting success with an IOP reduction to the mid-teens for 2 years on no medical therapy. The situation was much more settled, but without the haloes the patient started to notice a "haze" in front of his vision. This was due to a posterior subcapsular cataract that developed over a long period of time secondary to frequent use of topical steroid drops for keeping inflammation and fibrosis at bay postsurgery. He underwent an uncomplicated phacoemulsification with intraocular lens implant in December 2004, after which he developed postoperative cystoid macular edema confirmed on ocular coherence tomography. This was appropriately managed, but subsequently the cornea decompensated with epithelial edema in 2006. The patient underwent a penetrating keratoplasty in 2007 with a clear graft to date. The pressure remained controlled in the mid-teens until 2008, when he developed tube retraction in the second functioning Molteno drainage implant. Aggressive scarring response leads to a higher incidence of tube retraction. ${ }^{1-3}$

On discussion of the risks and benefits, it was decided that he undergo tube extension (see Surgical technique). Thereafter, on timoptol $0.5 \% \mathrm{bd}$, his pressure remained in the mid-teens (see Figure 1, last measured March 2010: $16 \mathrm{~mm} \mathrm{Hg}$ ), which to date has settled with preservation of the central island of vision and BCVA of 6/12.

A pre-existing angle anomaly that is further compounded due to persistent raised IOP and chronic inflammatory response secondary to previous multiple surgeries is often the cause of poor long-term structural and functional outcome in this case. Delayed implantation of drainage devices at a later age of 22 years might also in part have contributed to the poor surgical outcome. 
Glaucoma drainage device (GDD) surgery is now common in complex cases such as infantile glaucoma. The outcome of these procedures is encouraging and increasingly supports their use as first-line surgical options for the treatment of high-risk adult and juvenile glaucoma. ${ }^{4}$

This surgical intervention is contraindicated in patients who have borderline endothelial function and are unable to comply with self-care and close follow-up. Complications include hypotony, suboptimal raised IOP, tube retraction/ obstruction, diplopia, corneal decompensation/corneal graft failure, suprachoroidal hemorrhage, endophthalmitis, and resultant loss of vision.

\section{Surgical technique}

GDD tube retraction is a well recognized but uncommon complication. A variety of surgical devices has been used to extend drainage device tubes, namely 22-gauge angiocatheter, Crawford tubing, and Tube Extender ${ }^{\circledR}$ (New World Medical, Inc., Rancho Cucamonga, CA, USA). ${ }^{5}$ In this patient, a $4 \mathrm{~mm}, 22$-gauge angiocatheter (Venflon) cannula (see Figure 2) was used to connect the proximal and distal ends of the cut drainage tube where the distal end was advanced $4 \mathrm{~mm}$ into the anterior chamber with optimum positioning (see Figures 3 and 4).

The tube portion of the GDD was adequately exposed by careful conjunctival dissection. A $4 \mathrm{~mm}$ extending segment of 22-gauge intravenous catheter tubing was cut using a sharp blade. The distal end of the GDD tube was advanced $4 \mathrm{~mm}$ into the anterior chamber with optimal positioning (see Figure 3). The extending segment fit very securely over the cut ends of the tube proximally and distally. The segment was further secured with 10-0 nylon at each end (see Figure 3).

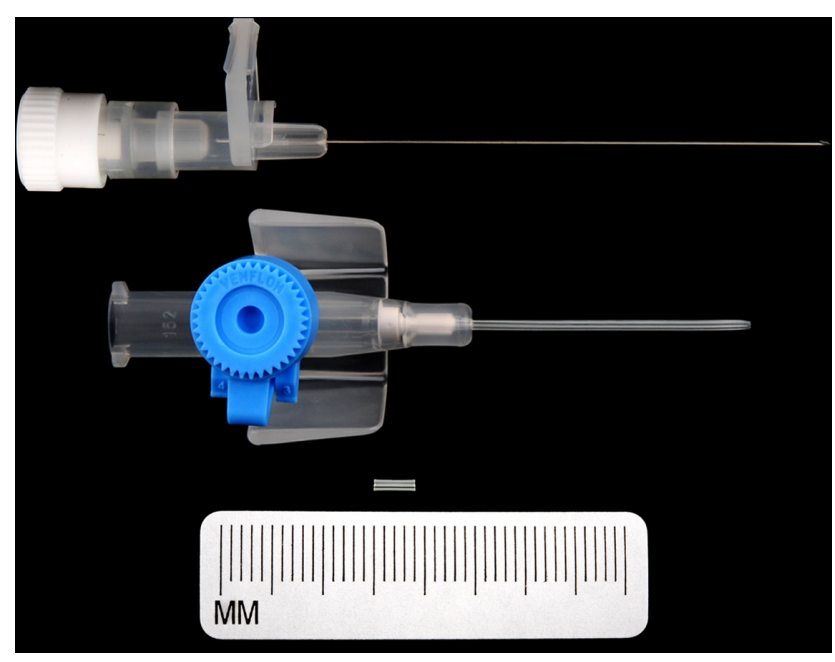

Figure 2 22-gauge angiocatheter (Venflon) cannula.

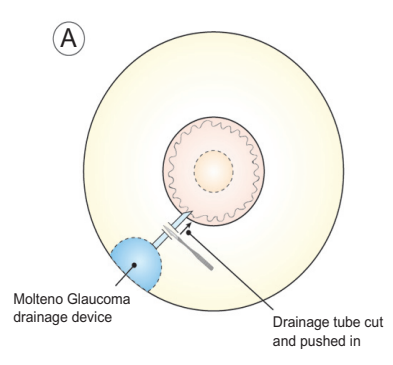

(B)

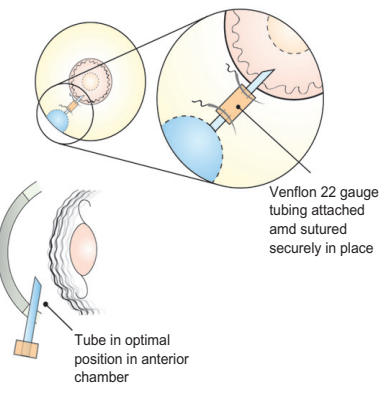

Figure 3 Salient features of the tube extension surgery.

An appropriately sized donor scleral patch graft was then placed over the tube, and 8-0 absorbable sutures were used to close the conjunctiva. Anterior chamber paracentesis was then performed and balanced salt solution injected to ensure patency of the tube. Viscoelastic was injected into the anterior chamber to prevent hypotony. This allowed for re-establishment of aqueous humor drainage and resultant control of IOP postoperatively. Great care must be taken that corneal endothelial touch due to the persisting shallow anterior chamber during initial phases of valve surgery is prevented. If not prevented or managed properly, intrusion of uveal tissue in the tube osteum can ensue, and subsequent fibrous ingrowth can occur within the tube.

The results of the successful use of alternative modality using an angiocatheter segment to extend GDD tubes were first described by Smith and Doyle. ${ }^{1}$ The technique used in this patient was similar to the one described by Bansal et al. ${ }^{6}$ They described two complex pediatric cases who required extension of retracted GDD tube. One case had satisfactory reduction in IOP, whereas the second case had only $25 \%$ reduction in IOP due to scarring over the plate. ${ }^{6}$

The Venflon cannula used to make the extension segment is biocompatible, as it is made of polytetrafluoroethylene (Teflon), which is an inert material and is used for making

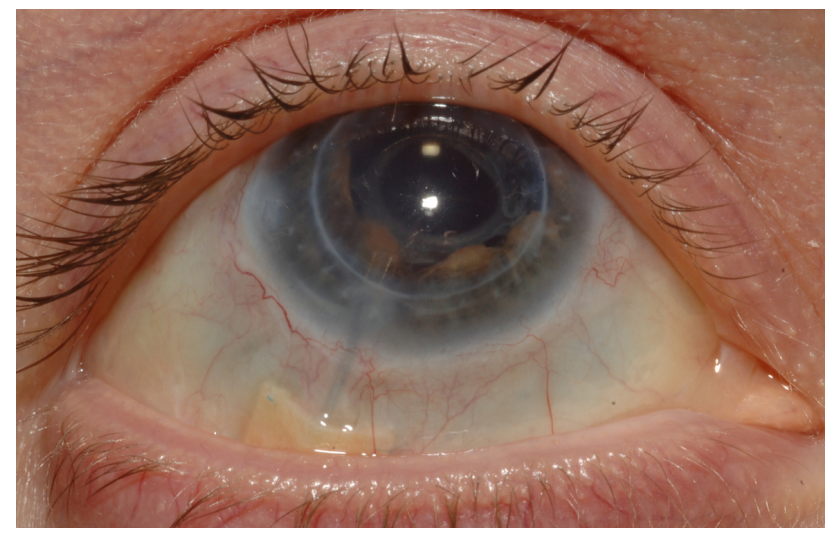

Figure 4 Postoperative appearance of optimal glaucoma drainage device tube position in anterior chamber. 
extensions for extraocular muscles ${ }^{7}$ and vascular prosthesis. ${ }^{8}$ It is also used in other parts of the body without any known long- term complications. ${ }^{9}$

The commercially available Tube Extender has been used to extend retracted GDD tubes. ${ }^{5}$ It is relatively expensive (\$200 per Tube Extender, compared with about $\$ 4$ per intravenous catheter). ${ }^{6}$ The main problem with its use is its distal end, which is relatively bulky and does not seem to be ideal for placement near the limbus. ${ }^{5}$ Further, it may be difficult to suture the relatively larger distal end if the sclera is already thin due to multiple glaucoma procedures, as in this case.

An alternative to tube retraction is repositioning the GDD anteriorly. This requires extensive dissection of conjunctiva and tenon's capsule and can lead to postoperative scarring, especially in this case. Implantation of a new GDD would be a major undertaking for this patient. Due to multiple glaucoma procedures, it would be technically challenging to inplant a third Molteno device.

\section{Conclusion}

Undoubtedly, management of congenital glaucoma and buphthalmos remains a challenging task. GDD provide an effective option for long-term IOP reduction in complex glaucoma cases. Nevertheless, they are not without complications.
In situations of tube retraction, the use of a 22-gauge angiocatheter allowed for restoration of adequate IOP control and was the best surgical option available due to the complexity associated with previous multiple glaucoma procedures.

\section{Disclosure}

The authors report no conflicts of interest in this work.

\section{References}

1. Smith MF, Doyle JW. Results of another modality for extending glaucoma drainage tubes. J Glaucoma. 1999;8:310-314.

2. Netland PA, Walton DS. Glaucoma drainage implant in pediatric patients. Ophthalmic Surg. 1993;24:723-729.

3. Munoz M, Tomey KF, Traverso C, et al. Clinical experience with the Molteno implant in advanced infantile glaucoma. J Pediatr Ophthalmol Strabismus. 1991;28:68-72.

4. Gedde SJ; The Tube Versus Trabeculectomy Study Group. Results from the Tube Versus Trabeculectomy Study. Middle East Afr J Ophthalmol. 2009;16(3):107-111

5. Fechter HP, Sarkisian SR, Budenz DL, et al. How Do I Extend a Tube? Glaucoma Today. January/February 2009:37-40.

6. Bansal A, Fenerty CH. Extension of retracted glaucoma drainage tube using 22-gauge intravenous catheter in complex pediatric glaucoma: surgical techniques. J Glaucoma. 2010;19(4):248-251.

7. Langmann A, Lindner S, Wackernagel W, et al. Polytetrafluoroethylene (Goretex) for muscle elongation in the surgical treatment of strabismus with restricted motility. Acta Ophthalmol Scand. 2006;84:250-253.

8. Paran TS, Corbally MT, Gross-Rom E, et al. Experience with aortic grafting during excision of large abdominal neuroblastomas in children. J Pediatr Surg. 2008;43:335-340.

9. Hurst BS. Permanent implantation of expanded polytetrafluoroethylene is safe for pelvic surgery. United States Expanded Polytetrafluoroethylene Reproductive Surgery Study Group. Hum Reprod. 1999;14:925-927.
Clinical Ophthalmology

\section{Publish your work in this journal}

Clinical Ophthalmology is an international, peer-reviewed journal covering all subspecialties within ophthalmology. Key topics include: Optometry; Visual science; Pharmacology and drug therapy in eye diseases; Basic Sciences; Primary and Secondary eye care; Patient Safety and Quality of Care Improvements. This journal is indexed on Submit your manuscript here: http://www.dovepress.com/clinical-ophthalmology-journal

\section{Dovepress}

PubMed Central and CAS, and is the official journal of The Society of Clinical Ophthalmology (SCO). The manuscript management system is completely online and includes a very quick and fair peer-review system, which is all easy to use. Visit http://www.dovepress.com/ testimonials.php to read real quotes from published authors. 